\title{
Recirculating Flow Injection Calorimetric Biosensor and Its Improved Performance Evaluation for Dichlorvos Detection
}

\author{
Yihua Zheng* and Jun Liu \\ Institute of Bioheat Sciences, College of Mechanical and Electrical Engineering, Qingdao University, \\ 308 Ningxia Road, Qingdao 266071, China
}

(Received April 17, 2017; accepted May 29, 2017)

Keywords: calorimetric biosensor, flow injection analysis, thermopile, progress curve, thermoelectric thermostat

A novel calorimetric biosensor is developed by recirculating flow injection analysis. The biosensor consists of a peristaltic pump, two switching valves, a thermostat, an injection valve, two twin cells (a reaction cell and a reference cell), a thermopile, a data acquisition module, and a personal computer (PC). This biosensor with an improved structure can respond to reaction heat timely by placing the thermopile between the reaction and reference cells. Enzymatic reaction will be continuous when an excessive substrate is introduced into the two cells and flows circularly through them. The calorimetric biosensor has been applied successfully in dichlorvos detection by a new test method. In this method, two parameters of constant response in the zero-order reaction phase and the transition moment from zero-order reaction to firstorder reaction are obtained from the progress curve of the enzymatic reaction. Under a certain initial enzyme activity derived from the transition moment, dichlorvos can be determined by comparing the difference in constant response caused by the enzymatic reaction with inhibition in the reaction cell and without inhibition in the reference cell. The performance shows a linear range of $0.01-0.5 \mathrm{mg} / \mathrm{L}$ with a relative standard deviation (RSD) of $3-10 \%$ and a limit of detection (LOD) of $0.01 \mathrm{mg} / \mathrm{L}$, as well as a detection duration of $20 \mathrm{~min}$. The system is fast, can repeatedly and easily be used, and can improve automation and prevent possible input errors. It is suitable for the rapid detection of pesticides in the field.

\section{Introduction}

Organophosphrous pesticides (OPs) are important contributors to pollution because of their widespread use in agriculture and are major concerns in the fields of environmental monitoring and food safety. ${ }^{(1-3)}$ However, field detection methods lag behind, and government regulation and effective control of OPs are weak. It is of great significance to explore an accurate, rapid, and easy field detection method and to develop sensors of OPs. ${ }^{(4)}$

Some biosensors, such as amperometric, potentiometric, colorimetric, conductometric and $\mathrm{pH}$ sensors, for the rapid determination of OPs have been reported. ${ }^{(5-7)}$ Their applications

*Corresponding author: e-mail: yihua.zheng@qdu.edu.cn

http://dx.doi.org/10.18494/SAM.2018.1628 
in real samples are limited because of interferences from electroactive species and ions and the turbidity of the samples. Owing to its universality and insusceptibility to optical, electrochemical and other inherent interferential factors of crude samples, the calorimetric biosensor may be a good tool for the rapid detection of pesticide residues. ${ }^{(8,9)}$ Moreover, calorimetric measurement is a robust technique and does not require frequent recalibration, which makes the system easier to use.

Most of the biorecognition elements reported to date for the biosensor detection of pesticides are based on their inhibitory nature for certain enzymes and immunoreactions for certain antibodies. ${ }^{(10,11)}$ Immunoassay is an emerging technique, which has great potentials in pesticide detection. Relatively, the enzyme inhibition method is simple, low-cost, specific, sensitive and suitable for rapid detection in the field and sample screening tests in bulk. Until now, the rapid determination of pesticides has usually been performed with the inhibitory action of OPs to acetyl-cholinesterase (AChE). However, AChE is difficult to obtain, preserve, and immobilize, and it is also expensive for disposable use. Practice shows that the chicken liver esterase can be used as an analytical reagent instead of AChE. ${ }^{(12)}$

In a previous study, ${ }^{(13)}$ a flow injection calorimetric biosensor was developed for the rapid determination of OPs in order to protect humans from acute toxicity. In the current apparatus, the thermal sensor is placed at the outlet of the reaction and reference cells, which has some limitations in compactness, automation, and particularly in its timely response to heat change in the two cells. The chicken liver esterase used as an analytical reagent instead of $\mathrm{AChE}$ is immobilized by enzymatic adsorption into the ion exchange resin for a low-cost and convenient method of preparation. However, the inherent poor adsorption results in the irregular loss of enzyme activity. This problem can be solved by further crosslinking the adsorption immobilized esterase with glutaraldehyde following adsorption immobilization. The determination of pesticides using the calorimetric biosensor is based on a conventional method of evaluating the relative degree of inhibition of the enzyme incubated with pesticides. In this method, measurement is conventionally made in several steps including those repeated. First, no inhibitor is used in order to establish the enzyme activity in the absence of the inhibitor, and then an inhibitor is added together with an enzyme. After incubation with the inhibitor, the enzyme activity in the presence of the inhibitor is determined by repeating the first step. The relative degree of inhibition is calculated from the enzyme activity with and without inhibition. The complicated measurement procedure results in extra interference, error accumulation, and the increase in time required for stabilizing baselines. In addition, the reference cell, which is set to virtually eliminate the effect of unspecified heat, requires a completely inactivated esterase with extra operation time and consumption cost.

Flow injection analysis (FIA) based on the recirculation of the reaction solution used has several advantages over other methods, i.e., saving samples and reagents, automated determination, and amplification. The application of recirculating FIA systems has been demonstrated in the estimation of kinetics, ${ }^{(14)}$ autocalibration, ${ }^{(15)}$ and interference removal. ${ }^{(16)}$

In this work, we developed a recirculating flow injection calorimetric biosensor with an improved structure consisting of a thermopile, a reaction cell, and a reference cell as well as an enhanced stability of immobilized chicken liver esterase. On the basis of a fast and easy test method, the calorimetric biosensor has been applied to the determination of dichlorvos 
using progress curve data. The evaluation results show that the system has good performance in monitoring enzyme reaction with inhibition and is suitable for availability on determining pesticides and other inhibitors.

\section{Measurement Principle}

For an enzyme-substrate system, if the initial concentration of the substrate is much greater than the Michaelis constant $\left([S]_{0} \gg K_{M}\right)$, the enzyme reaction will be on the zero order and its reaction rate will be constant, which is determined by the enzyme activity and is independent of the substrate concentration. The progress curve of the reaction rate with time can be plotted as a flat straight line in the beginning [see Fig. 1 (a), Time $<T$ ]. With the continuous depletion of the substrate, the enzyme reaction will transform from being a zero-order reaction to being a first-order one at the transition moment $T$. The rate of the first-order reaction depends on and is directly proportional to the substrate concentration, which results in the reaction rate declining with the decrease in the substrate concentration [see Fig. 1(a), Time $>T$ ]. If the initial concentration and volume of the substrate are specified, the reaction rate and transition moment from the progress curve will correspond to the enzyme activity. It is clear that the enzyme reaction with a higher enzyme activity has a higher reaction rate and a shorter transition moment.

The reference and reaction cells are packed with the same batch of the immobilized enzyme with the initial enzyme activity in the calorimetric biosensor. The primary information provided by the measurement of the reaction rate is that regarding the thermometric responses provoked by heat effects in the reference and reaction cells. When the immobilized enzyme of the reaction cell is incubated with the inhibitor, the enzyme activity becomes different for the immobilized enzyme in reference and reaction cells owing to the presence of the inhibitor. The difference depends on the degree of inhibition and represents the concentration of the inhibitor. The thermometric responses for the reference and reaction cells are shown in Fig. 1(b) with the continuous consumption of the substrate when excessive substrate flows circularly through them. According to the above principle, the thermometric responses of the reference and reaction cells are constant and proportional to their respective enzyme activities in the

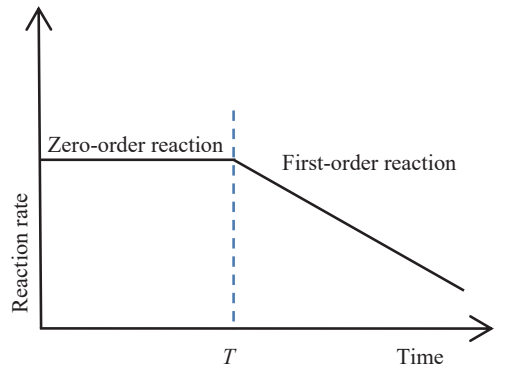

(a)

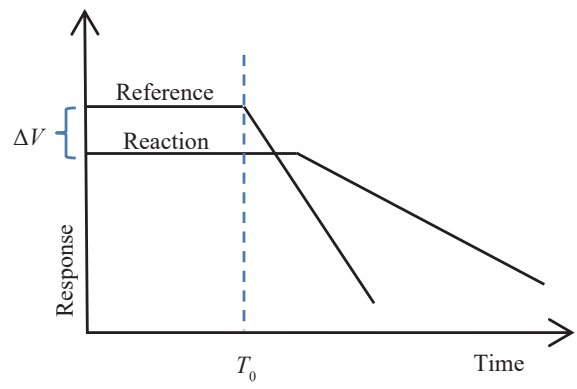

(b)

Fig. 1. (Color online) Schematic progress curves for enzyme reaction. (a) Enzyme-substrate system and (b) calorimetric biosensor. 
zero-order reaction phase. Therefore, the response difference $\Delta V$ between the reference and reaction cells is caused by enzyme activity discrepancy and also represents the concentration of the inhibitor. Owing to the enzyme without inhibition, the enzyme reaction in the reference cell will transform from being zero order to being first order in advance. Once the response difference $(\Delta V)$ starts to decline, the transition moment $T_{0}$ occurs, and the initial enzyme activity can be further derived by referring to the standard relationship between the enzyme activity and the transition moment. On the basis of the results of the above analysis, the inhibitor can be determined in single steps by referring to the standard relationship between the concentration of the inhibitor and the response difference $(\Delta V)$ with a certain initial enzyme activity.

\section{Materials and Methods}

\subsection{Materials}

Fresh chicken liver was supplied by Shanghai Dajiang Food Company. D113 ion exchange resin was purchased from Tianjin Nankai Chemical Plant. Dichlorvos was purchased from Shanghai Pesticides Company, glutaraldehyde and a-naphthyl acetate were purchased from Sigma Company, and other reagents were of analytical grade.

The wet D113 resin between 35 and 40 meshes was dehydrated by centrifugation and then stirred with $0.5 \mathrm{M} \mathrm{NaOH} / \mathrm{HCl}$ solution in the sequence of $\mathrm{NaOH}-\mathrm{HCl}-\mathrm{NaOH}$ for $12 \mathrm{~h}$. The fresh chicken liver was mixed with citric acid buffer $(0.025 \mathrm{M}, \mathrm{pH} 6.4)$ at $1 \mathrm{~g} / \mathrm{ml}$. The mixture was homogenized using a tissue triturator (Model DS-1, Shanghai Sampling Model) and then separated for $10 \mathrm{~min}$ at $5000 \mathrm{rpm}$ using a centrifuge (Model 90-1, Beijing General Centrifuge Works). The final supernatant was diluted to a $6 \pm 2 \mathrm{U} / \mathrm{ml}$ enzyme activity with citric acid buffer $(0.025 \mathrm{M}, \mathrm{pH}$ 6.4). The adsorption-immobilized esterase was obtained by mixing the diluted esterase and pretreated D113 resin at $3 \mathrm{ml} / \mathrm{g}$, followed by stirring for $75 \mathrm{~min}$. The adsorption-crosslinking-immobilized esterase was obtained by adding the adsorptionimmobilized esterase to a $0.04 \%$ glutaraldehyde solution, and then the mixture was stirred for $60 \mathrm{~min}$ at $10{ }^{\circ} \mathrm{C}$. After immobilization, the immobilized esterase was separated and washed repeatedly with deionized water until no enzyme was left in the water.

\subsection{Calorimetric biosensor}

The schematic of the calorimetric biosensor is shown in Fig. 2. The biosensor is an FIA system primarily consisting of a peristaltic pump, two switching valves, a thermostat, an injection valve, a reaction cell, an identical reference cell, a thermopile, a data acquisition module, and a personal computer (PC). During operation, two identical weights of the resin with chicken liver esterase are each packed into the reaction cell (7) and reference cell (8). The disturbances from room temperature and unspecific heat between the two cells can be markedly reduced by differential measurement between the reaction and reference cells. The six-way valve (1) can mix the analyte, buffer and other reagents. The mixed solution passes through 


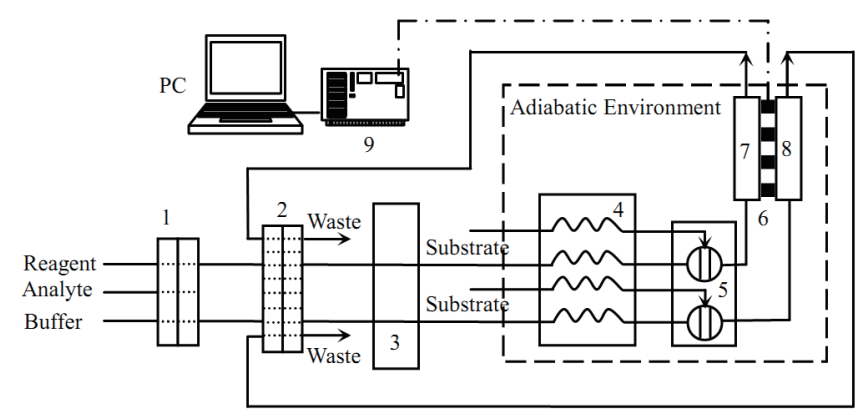

Fig. 2. Calorimetric biosensor. (1) Six-way valve, (2) sixteen-way valve, (3) peristaltic pump, (4) thermostat, (5) injection valve, (6) thermopile, (7) reaction cell, (8) reference cell, and (9) data acquisition module.

the thermostat (4) with a constant temperature and then enters the two cells simultaneously through the peristaltic pump (3) with a constant flow rate. The thermostat and thermoelectric cooler/heater can be adjusted into the range of 0 to $70{ }^{\circ} \mathrm{C}$ with temperature constancy within $\pm 0.2^{\circ} \mathrm{C}$. By switching the six-way valve (2), the system can be used either in the single-flow mode, in which the solution is treated as waste after flowing through the two cells, or in the recirculation mode, in which the solution continuously flows through the two cells circularly. The enzymatic reaction occurs simultaneously in the two cells when substrates are introduced into the system using the injection valve (5). The thermopile (6) used as a thermal sensor records the temperature difference between the reaction and reference cells. It is a series of four thermocouple plates (TEC1-03104, $15 \times 15 \times 3 \mathrm{~mm}^{3}$, from Taicang TE Cooler, China) including 73 pairs of serial BiTe thermocouples. The DAQ, which has a 24-bit resolution and a 64-fold gain, acquires the potential signal from the thermopile and couples the PC with the USB. The monitoring program written by Labview records and saves the potential signal data in Microsoft Office Excel for further processing.

Figure 3 illustrates the improved structures of the thermopile, reaction cell, and reference cell. The two cells are twin cylindrical spaces encircled with the corresponding upper plunger, down plunger, and copper reactor. The volumes of the two cells can be optimized by adjusting the position of the upper plunger and replacing reactors with different inner diameters. The thermopile is placed between the two cells and kept in close contact. The structure is compact and automated. Furthermore, it responds to heat change more timely than the traditional detection system in the outlet.

\subsection{Determination of enzyme activity}

The immobilized chicken liver esterase was loosely slurry-packed into the reaction cell. The reference cell was filled with the same batch of the immobilized esterase, which was completely inactivated by $100 \mathrm{mg} / \mathrm{L}$ dichlovrvos for $10 \mathrm{~min}$. The system was operated in the recirculation mode and the thermostat was stabilized at $37{ }^{\circ} \mathrm{C}$ and a stream of buffer $(1.5 \mathrm{ml} / \mathrm{min})$ was pumped through the entire system. After a stable baseline was achieved, the enzyme reaction 


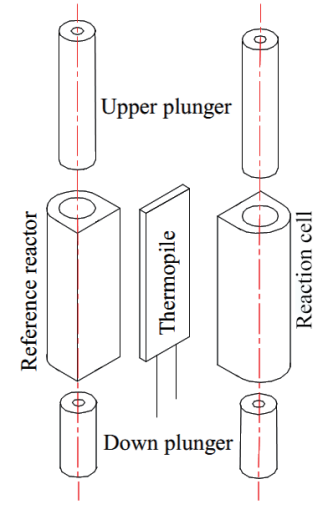

Fig. 3. (Color online) Structures of thermopile, reaction cell, and reference cell.

began to proceed with the introduction of $2 \mathrm{ml}$ of the substrate into the system. The temperature difference between the reaction and reference cells was recorded using the thermopile.

\subsection{Detection of dichlorvos}

The reaction and reference cells were loosely slurry-packed with the same batch of immobilized chicken liver esterase. The system was operated in the recirculation mode, and the thermostat was stabilized at $37^{\circ} \mathrm{C}$ and the stream of buffer $(1.5 \mathrm{ml} / \mathrm{min})$ was pumped through the entire system. After a stable baseline was achieved, the reaction cell was incubated for 5 min as preinhibition with citric acid buffer $(0.025 \mathrm{M}, \mathrm{pH}$ 6.4) containing dichlorvos of known concentration, for simulating the sample, while the reference cell was simultaneously incubated with citric acid buffer. Then, dichlorvos was detected by introducing $2 \mathrm{ml}$ of the substrate into the system. The temperature difference between the reaction and reference cells was recorded using the thermopile, and the transition moment was also obtained when the temperature difference decreased to a miminal level. The resin with chicken liver esterase was disposable in every testing.

\section{Results and Discussion}

\subsection{Optimization of system parameters}

System variables were optimized in order to obtain the highest analytical response and performance. Table 1 shows the studied range and optimum parameters.

The detection temperature should be set as a point at which the enzyme activity of esterase is high and stable. Furthermore, a great departure of the detection temperature from the environment temperature requires a higher control ability for the thermostat. The reference temperature for the enzyme catalytic reaction is modified from 30 to $37^{\circ} \mathrm{C}$ as recommended by the International Federation of Clinical Chemistry (IFCC). ${ }^{(17)}$ The detection temperature of 37 ${ }^{\circ} \mathrm{C}$ was chosen. 
Table 1

Optimization of system parameters.

\begin{tabular}{lcc}
\hline & Studied range & Optimum \\
\hline Detection temperature $\left({ }^{\circ} \mathrm{C}\right)$ & $20-70$ & 37 \\
Flow rate $(\mathrm{ml} / \mathrm{min})$ & $0.1-5.0$ & 1.5 \\
Incubation time $(\mathrm{min})$ & $1-15$ & 5 \\
Initial concentration of substrate $(\mathrm{mM})$ & $5-250$ & 200 \\
Sample volume $(\mathrm{ml})$ & $1-5$ & 2 \\
Substrate volume $(\mathrm{ml})$ & $0.5-5$ & 2 \\
Inner diameter of cells $(\mathrm{mm})$ & $4,7,10$ & 7 \\
Length of cells $(\mathrm{mm})$ & $0-60$ & 55 \\
\hline
\end{tabular}

The flow rate affects the analytical response and detection duration. A high flow rate produces a high resolution and an unstable response signal. Considering low noise, the flow rate of $1.5 \mathrm{ml} / \mathrm{min}$ was determined to obtain a sufficient response.

Experiments with different inhibition times (incubation with dichlorvos from 1 to $15 \mathrm{~min}$ ) show that the degree of inhibition becomes constant when the inhibition time reaches $5 \mathrm{~min}$. Thus, the inhibition time of 5 min was selected for good repeatability.

The immobilized chicken liver esterase has $K_{M}$ of $0.733 \times 10^{-7} \mathrm{mM}$, as determined by kinetics analysis. The response changes when the concentration of the substrate is close to the relationship of Michael's equation and does not increase markedly when the concentration of the substrate is higher than $100 \mathrm{mM}$. Thus, $200 \mathrm{mM}$ was selected as the initial concentration of the substrate.

The injection volumes of both the substrate and the sample, and the inner diameter and length of the cells strongly affect the dispersion of reagents, response, and detection duration. Such parameters were determined by considering all factors.

\subsection{Sensitivity of thermopile}

The test of thermopile sensitivity was performed using two streams of buffer simultaneously flowing through the reaction and reference cells. One stream has a constant temperature of $20{ }^{\circ} \mathrm{C}$ and the other has a temperature in the range of $5-70{ }^{\circ} \mathrm{C}$ with $5{ }^{\circ} \mathrm{C}$ interval. The thermoelectric potential signals of the thermopile were recorded. The relationship between the potential and the temperature difference of the two streams is linear as shown in Fig. 4. The two straight lines, expressing the reversed arrangements of the two streams, have slopes of 4 and $3.88 \mathrm{mV} / \mathrm{K}$. The difference in slope is due to some manufacturing or material factors. The sensitivity of 4 or $3.88 \mathrm{mV} / \mathrm{K}$ is sufficient for detecting heat change due to enzymatic reaction.

\subsection{Determination of enzyme activity}

Figure 5(a) gives the progress curves of enzyme reaction with different enzyme activities. After a short lag phase, a linear phase with constant potential is obtained and remains when the substrate is still at saturation levels. The curves of the linear phase have a minor slope because of a possible substrate inhibitory effect, and the constant potential increases directly in 


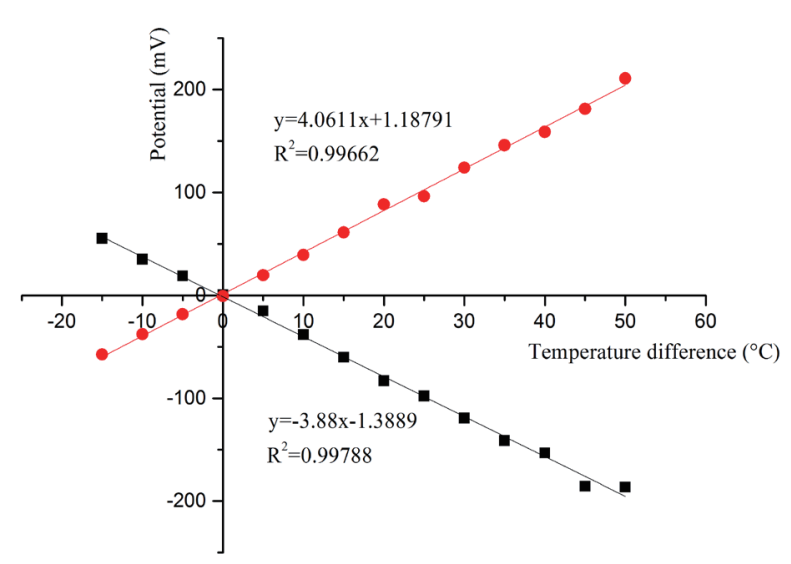

Fig. 4. (Color online) Sensitivity of thermopile.

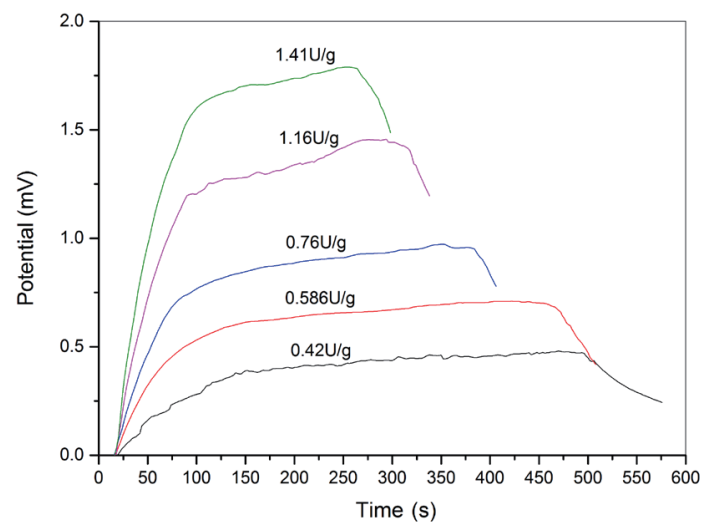

(a)

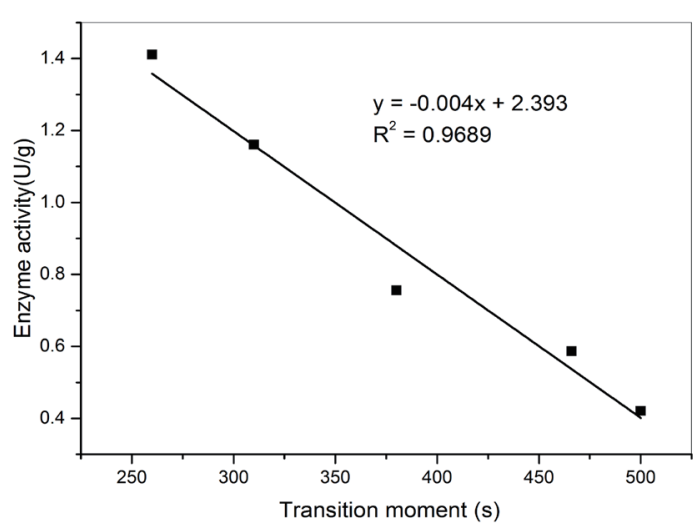

(b)

Fig. 5. (Color online) (a) Progress curves of enzyme reaction with different enzyme activities and (b) relationship between enzyme activity and transition moment.

proportion to the enzyme activity. With the continuous reaction and substrate being consumed to a relatively low concentration, the potential begins to decline after the transition moment.

From the progress curves shown in Fig. 5(a), the relationship between the enzyme activity and the transition moment is obtained and shown in Fig. 5(b). The relationship is close to linear and can be used to determine the initial enzyme activity of the immobilized esterase, which is a precondition in the practical measurement for compensating fluctuations in enzyme activity and screening a disabled immobilized esterase.

\subsection{Detection of dichlorvos}

Under the established working condition, the progress curves of enzyme reaction inhibited by different dichlorvos concentrations are given in Fig. 6(a) and the relationship between the potential and the dichlorvos concentration is further analyzed as shown in Fig. 6(b). The initial enzyme activity of $1.34 \mathrm{U} / \mathrm{g}$ can be determined by referring to the relationship shown in 


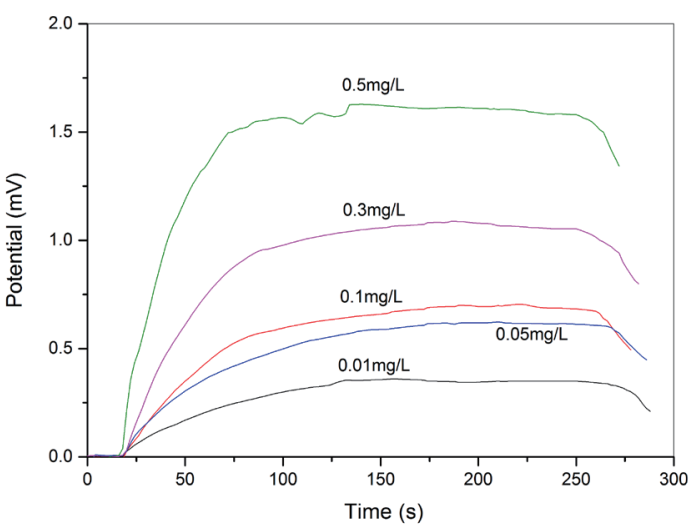

(a)

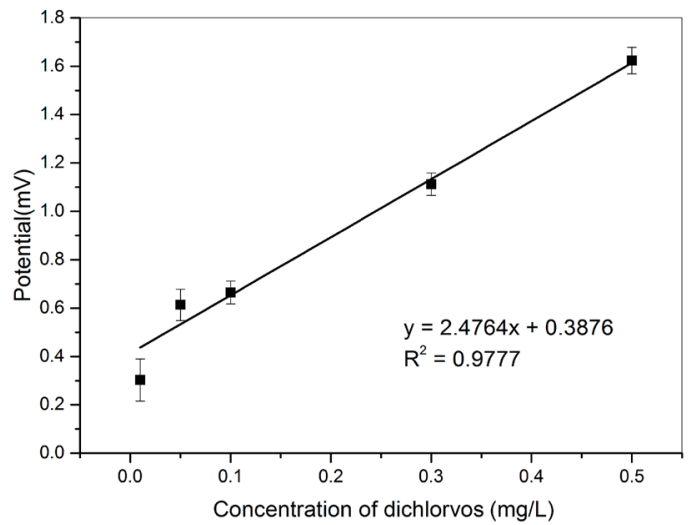

(b)

Fig. 6. (Color online) (a) Progress curves of enzyme reaction with different dichlorvos concentrations and (b) relationship between potential and dichlorvos concentration.

Fig. 5(b) based on the transition moment of $263 \mathrm{~s}$, which is obtained from the progress curves shown in Fig. 6(a). It can be seen from Fig. 6(b) that the potential increases proportionally with the increase in dichlorvos concentration within a linear range of 0.01 to $0.5 \mathrm{mg} / \mathrm{L}$ at the initial enzyme activity of $1.34 \mathrm{U} / \mathrm{g}$. Therefore, according to this linear relationship, the concentration of dichlorvos can be determined by recording the potential signals.

An obvious decreasing tendency from 0.05 to $0.01 \mathrm{mg} / \mathrm{L}$ is observed in Fig. 6(b). In addition, we do not obtain effective results after several trials when the concentration of dichlorvos is less than $0.01 \mathrm{mg} / \mathrm{L}$. Thus, the limit of detection (LOD) for detecting dichlorvos is $0.01 \mathrm{mg} / \mathrm{L}$ in this system, which could completely meet the national standard requirement $(<0.2 \mathrm{mg} / \mathrm{L})$. Compared with the previous work, the LOD here improvs from 0.1 to $0.01 \mathrm{mg} / \mathrm{L}$.

The results shown in Fig. 6(b) are experimental data (mean \pm SD) for three tests with the same batch of enzyme and measurement conditions. The relative standard deviations (RSDs) are $28 \%$ for the dichlorvos concentration of $0.01 \mathrm{mg} / \mathrm{L}$ and $5 \%$ for the dichlorvos concentration of $0.2 \mathrm{mg} / \mathrm{L}$. For other concentrations, the RSD is in the range of 3 and $10 \%$.

The detection duration of this calorimetric biosensor is within 20 min including the preinhibition step. By using the developed calorimetric biosensor and proposed test method, the portable system is observed to be feasible for a rapid field test of OPs in order to protect humans from acute toxicity. Research and development for practical application can be further expected with the accurate judgment of the transition moment.

\subsection{Storage and operational stability of the immobilized esterase}

To investigate its operational stability, the immobilized chicken liver esterase was packed into the reaction cell and the calorimetric biosensor run with a buffer flux of $1.5 \mathrm{ml} / \mathrm{min}$ at $37^{\circ} \mathrm{C}$ for $30 \mathrm{~min}$. It was found that the enzyme activity of the adsorption-crosslinking-immobilized esterase is unaltered after running, while that of the adsorption-immobilized esterase reaches $30 \%$. 
After the esterase immobilized by the adsorption and adsorption-crosslinking methods was stored at $4{ }^{\circ} \mathrm{C}$, we tested the storage stability of the immobilized chicken liver esterase by monitoring the variation in enzyme activity day by day for a month. The enzyme activity loss reaches $50 \%$ at the sixth day for the adsorption-immobilized esterase, while the activity of the adsorption-crosslinking-immobilized esterase remains nearly constant for two weeks. The storage stability observed after two weeks is practically feasible for the disposable use of the immobilized esterase.

The operational and storage stabilities of the immobilized esterase prepared by the adsorption-crosslinking method are clearly found to be much higher than those of the esterase prepared by the adsorption method.

\section{Conclusions}

A novel calorimetric biosensor based on recirculation with a rapid and simple test method for the quantitative analysis of dichlorvos at toxic and hazardous levels is demonstrated. The structure of the system has been improved by placing a thermopile between the reaction and reference cells. Compared with the adsorption-immobilized esterase, the adsorptioncrosslinking-immobilized esterase shows improved storage and operational stabilities.

The results indicate that the system has good performance for dichlorvos detection. The potential is linearly proportional to the dichlorvos concentration from 0.01 to $0.5 \mathrm{mg} / \mathrm{L}$ with an RSD of $3-10 \%$ and an LOD of $0.01 \mathrm{mg} / \mathrm{L}$. According to the highlights of this study, many OPs will be considered using this system in future studies.

Considering the simplicity of the test, the automation of operation per assay and potential integration to a portable system, the developed calorimetric biosensor satisfies the regulatory requirement for rapid detection in the field. Also, its detection of a wide range of inhibitor compounds endows the developed calorimetric biosensor with a huge demand and capability in the fields of agriculture, environmental monitoring, and food safety.

\section{Acknowledgments}

The work was supported by the National Natural Science Foundation of China (Grant No. 50806036), Natural Science Foundation of Shandong Province (Grant No. ZR2014EEM004), and Primary Research \& Development Plan of Shandong Province (Grant No. 2015GSF117019).

\section{References}

1 G. Peng, Q. He, Y. Lu, D. Mmereki, and Z. Zhong: Environ. Sci. Pollut. Res. 12 (2016) 1.

2 D. Sharma, A. Nagpal, Y. B. Pakade, and J. K. Katnoria: Talanta 82 (2010) 1077.

3 M. H. Facure, L. A. Mercante, L. H. Mattoso, and D. S. Correa: Talanta 167 (2017) 59.

4 W. Zhang and W. L. Shan: Agrochemicals 23 (2015) 97.

5 S. Hassani, S. Momtaz, F. Vakhshiteh, A. S. Maghsoudi, and M. R. Ganjali: Arch. Toxicol. 45 (2016) 1.

6 B. Wang, C. Ye, X. Zhong, Y. Chai, and S. Chen: Electroanalysis 28 (2016) 304.

7 S. Qian and H. Lin: Anal. Chem. 87 (2015) 5395.

8 B. Mattiasson, B. Danielsson, C. Hermansson, and K. Mosbach: FEBS Lett. 85 (1978) 203. 
9 S. Pirvutoiu, I. Surugiu, E. S. Dey, A. Ciucu, V. Magearu, and B. Danielsson: Analyst 126 (2001) 1612.

10 S. P. Chandra and C. Nidhi: Anal. Biochem. 429 (2012) 19.

11 Y. F. Li, Y.-M. Sun, R. C. Beier, H. T. Lei, and S. Gee: TrAC Trends Anal. Chem. 88 (2017) 25.

12 H. J. Zhang, X. Q. Xu, F. Xu, and Z. Z. Hua: Chin. J. Anal. Chem. 32 (2004) 1421.

13 Y. H. Zheng, T. C. Hua, D. W. Sun, J. J. Xiao, F. Xu, and F. F. Wang: J. Food Eng. 74 (2006) 24.

14 V. Stefuca, A. Welwardova, and P. Gemeiner: Anal. Chim. Acta 355 (1997) 63.

15 V. Stefuca, I. Cipakova, and P. Gemeiner: Thermochim. Acta 378 (2001) 79.

16 M. Garrido, A. G. Lista, M. Palomeque, and B. S. Band: Talanta 58 (2002) 849.

17 M. Panteghini and J. Forest: Clin. Chim. Acta 355 (2005) 1. 